\title{
SUBSIDIOS GUBERNAMENTALES PARA RIESGOS DE MERCADO EN GRANOS: EL CASO DEL SORGO EN MÉXICO
}

\author{
Flavia Echánove Huacuja \\ Instituto de Geografía, Universidad Nacional Autónoma de México \\ Avenida Universidad 3000, México DF. 04510 \\ flavia2451@gmail.com
}

\begin{abstract}
Resumen: En un contexto de gran volatilidad de los precios internacionales de los granos, como el vivido en los últimos años, la protección a los productores adquiere gran relevancia. Con este fin, el gobierno de México implementó un programa de subsidios llamado agricultura por contrato, cuyas características y limitantes son el objeto central de nuestro estudio. Entre los hallazgos, se encontró que si bien dicho programa ofrece importantes ventajas para los participantes, es sumamante vulnerable por los inclumplimientos de contratos motivados por los efectos adversos del clima, la relación de precios relativos (precios internacionales vs precios en el mercado libre) y la evolución del tipo de cambio. Otras limitantes son la reducida cobertura nacional y la concentración de los apoyos en un reducido grupo de beneficiarios, entre los que figuran grandes empresas alimentarias.
\end{abstract}

Palabras clave: agricultura por contrato, coberturas de precios, subsidios, política agrícola, México.

\begin{abstract}
In a context of extreme price volatility related with agricultural commodities, as the one present during the last years, the producer protection is very relevant. For this purpose, the Mexican government established a program called contract farming, which characteristics and limitations is the object of this study. We found that the program offers important benefits to the participants, although is very vulnerable given the contract breach related to climatic disasters, the relation between prices (international vs. domestic) and the evolution of the exchange rate. Other obstacles of the program are the reduced national coverage
\end{abstract}

* Recibido: 11-05-12. Aceptado: 11-09-12. 
and the concentration of subsidies in a reduced group of beneficiaries, among them relevant agribusiness.

Keywords: contract farming, price hedging, subsidies, agricultural policy, Mexico.

\section{Introducción}

Desde los años treinta y hasta la crisis de 1982, el gobierno mexicano tuvo un elevado grado de intervención y regulación en la cadena alimentaria, protegiendo al sector agropecuario de la competencia externa y canalizándole importantes subsidios y transferencias públicas (Appendini, 2008; Paz y Palacio, 2009; Yúnez y Barceinas, 2000). En el caso de los granos y oleaginosas, principales productos agrícolas del país, el gobierno fijaba precios mínimos de venta (precios de garantía) que beneficiaban a los agricultores en función del volumen producido; regulaba el mercado interno y externo de esos bienes y otorgaba subsidios a la comercialización, la adquisición de insumos (fertilizantes, semillas y agua) y los servicios (crédito y aseguramiento). Esto último lo hacía a través de empresas e instituciones propias, aunque también operaba otras que procesaban toda una gama de bienes (alimentos balanceados, azúcar, leche, aceites, harinas, etc.). La realización de investigación y la asesoría técnica eran otras actividades en las que el gobierno intervenía. En este contexto, jugó un papel central el organismo estatal CONASUPO (Compañía Nacional de Subsistencias Populares), creado en 1965, que tenía como principal actividad la de regular el mercado de granos básicos (maíz, frijol, arroz y trigo) mediante su compra (a precios de garantía), almacenamiento, procesamiento, distribución y otorgamiento de permisos para su importación. El control sobre los precios al consumidor de productos básicos era también labor del gobierno, que incluso tenía sus propias tiendas para ofrecerlos a los sectores más pobres de la población rural y urbana (Yúnez y Barceinas, 2000).

Sin embargo, durante la década de los ochenta, tanto en México como en América Latina y el resto de los países en desarrollo, se empezaron a aplicar políticas de ajuste estructural en respuesta a la crisis de sus deudas externas, que implicaron la retirada del Estado del funcionamiento de sus economías y el tránsito de las restricciones al comercio y el intervencionismo en el mercado hacia la liberalización comercial (OECD, 2010; Reinhardt y Peres, 2000). Esta última enmarcada, en el caso mexicano, en claves tratados comerciales como el Acuerdo General de Aranceles Aduanales y Comercio (GATT, ahora WTO), firmado en 1986 y el Tratado de Libre Comercio de América del Norte (TLCAN), iniciado en 1994, el cual, después de un período de transición de catorce años, dio lugar a la completa apertura comercial entre Estados Unidos, Canadá y México en 2008. 
En ese contexto, la crisis de la deuda de México de 1982 obligó al gobierno a abandonar su costosa política de oferta interna de alimentos baratos a precios subsidiados (Appendini, 2008). En ese año inicia el desmantelamiento de CONASUPO, que culmina con su cierre en 1998, desapareciendo también durante ese lapso casi todas las empresas e instituciones estatales que tenían ingerencia en la cadena alimentaria, incluyendo Banrural, principal institución crediticia para los productores agropecuarios. El resultado fue la eliminación o reducción de los subsidios a los servicios e insumos, a lo que se sumó la eliminación de los precios de garantía de los granos y oleaginosas en 1989, salvo los de maíz y frijol, que desaparecen en 1995. Todo ello, aunado a la liberalización comercial producto del TLCAN, que abrió las fronteras mexicanas a la importación de granos de Estados Unidos a precios subsidiados ("dumping"), es decir, menores a sus costos de producción (Wise y Rakocy, 2010), incrementó la dependencia alimentaria del país y desplomó los precios internos de esos bienes (Fox y Haight, 2010a; Wise, 2010). Estos precios empezaron a repuntar hasta fines de 2006, como efecto del alza de las cotizaciones internacionales.

Consecuentemente, la política de subsidios del gobierno mexicano hacia el sector agropecuario es reorientada, cambiando su enfoque e instrumentos, pero sin dejar de intervenir activamente en el mercado de granos. Hasta hoy se ha asentado fundamentalmente en tres pilares: pagos directos a los productores, subsidios para la adquisición de equipo e infraestructura productiva y apoyos a la comercialización. Estos últimos se han enfocado a proteger, tanto a productores como a empresas compradoras de granos, de los riesgos de fluctuaciones en los precios internacionales de esos bienes, y han sido los apoyos que mayor dinamismo han tenido en los últimos años en términos del volumen de productos apoyados y de los recursos gubernamentales asignados. Sin embargo, han sido los menos estudiados en México por parte de investigadores independientes, salvo, como señala Fox y Haight (2010a: 26), las notables excepciones de los trabajos de CEDRSSA (2007), Echánove (2009) y Steffen (2007). El objetivo de este artículo es el de ampliar el conocimiento sobre dicho tema, para lo cual analizaremos las características, limitantes y efectos de los programas de coberturas de precios y agricultura por contrato, que son los principales componentes de los subsidios a la comercialización. Elegimos el caso del sorgo, el tercer producto más apoyado por dichos programas y segundo en importancia dentro de los granos producidos en México. Constituye, además, un insumo básico para la elaboración de alimentos animales, cuya producción ubica a dicho país en cuarto lugar a nivel mundial (ALLTECH, 2012; IFIF, 2011).

La metodología utilizada en la investigación consistió fundamentalmente en la realización de 30 entrevistas directas a profundidad en Tamaulipas y Guanajuato, que constituyen los dos principales estados productores de sorgo en México. Los agentes entrevistados fueron aquellos que participan en la cadena de producción y comercialización de dicho grano, tanto de carácter público como privado. Estos incluyeron productores individuales y representantes o líderes de sus organizaciones, gerentes y 
otros miembros de las principales firmas que comercializan el sorgo, gerentes y/o encargados de compras de agroindustrias elaboradoras de alimento animal, y funcionarios gubernamentales encargados del diseño y operatividad de los programas de subsidios objeto de nuestro estudio. También se analizó información estadística y hemerográfica, literatura publicada y aservos de noticias periodísticas.

En un primer apartado se describen los cambios centrales de la política agrícola mexicana, mientras que en un segundo se analizan las características de los programas de riesgos de precios. Los dos siguientes apartados se centran en los hallazgos de los estudios de caso llevados a cabo en las entidades mencionadas y, en el último, se presentan las reflexiones finales.

\section{Cambios en la política agrícola: la expansión de los subsidios para riesgos de precios}

Como ya mencionamos, uno de los pilares de la actual política agrícola de México son los pagos directos a los productores. El programa que se encarga de este tema es el PROCAMPO (Programa de Apoyos Directos al Campo), iniciado en 1994, y que consiste en el otorgamiento al productor de un pago monetario por unidad de superficie sembrada (independientemente del volumen producido), equivalente a los pagos desacoplados de la Unión Europea, Estados Unidos y otros países. El PROCAMPO es hasta hoy el programa de apoyo al sector agropecuario más relevante, dado el número de productores beneficiados, la superficie apoyada y el presupuesto asignado. Apoya a 2.8 millones de productores (autoconsumo y comerciales), los cuales representan casi la mitad de los ocupados en el sector primario, así como a alrededor de 14 millones de hectáreas, es decir, al 64\% de la superficie agrícola cultivada a nivel nacional. Se instrumentó como un mecanismo sustitutivo del anterior esquema de precios de garantía, para, de acuerdo al gobierno, compensar a los productores mexicanos de los subsidios otorgados a sus contrapartes de otros países que concurren al mercado internacional (ASERCA, 2011a).

El segundo fundamento de la política agrícola se contiene en el programa Apoyo a la Inversión en Equipamiento e Infraestructura, que inició en 1996 bajo el nombre de "Alianza para el Campo". Estos subsidios, a diferencia de los dados por PROCAMPO, están dirigidos solo a productores con cierto grado de capitalización y excedentes comercializables, es decir, se excluye al universo de los de autoconsumo, no obstante lo cual en 2011 se les asignó un presupuesto ligeramente menor al de PROCAMPO. El tercer pilar, los apoyos a la comercialización, iniciaron en 1991, pero solo hasta 2003 se empieza a aplicar una política integral que incluye tanto subsidios vía precios (Ingreso Objetivo) como otro tipo de apoyos (coberturas de precios, agricultura por contrato, pignoración de cosechas, fletes terrestres, promoción de exporta- 
ciones, etc.). El Ingreso Objetivo consistió en un apoyo a los productores de ciertos granos que cubría la diferencia entre un "precio objetivo", fijado cada cinco años por el gobierno, y el precio de mercado. Sin embargo, y en contraste con los anteriores precios de garantía, este apoyo se otorgaba solo a los productores comerciales, es decir, a los que acudían al mercado a vender sus cosechas (Steffen, 2007).

Hasta 2006, el Ingreso Objetivo fue el principal componente de los subsidios a la comercialización (OECD, 2011a), aunque apoyó a un muy reducido número de productores (144.000 al año en promedio). A partir de 2007 prácticamente desapareció, ya que los precios fijados quedaron muy por debajo de los crecientes precios internacionales de los granos (Echánove, 2009). Es a partir de entonces que el grueso de los recursos para apoyar la comercialización de bienes agropecuarios se destina a proteger a los productores y compradores de granos básicos y forrajeros de los riesgos del mercado, fundamentalmente de las fluctuaciones de los precios internacionales, tratando de otorgar con ello una mayor certidumbre en los ingresos de dichos agentes.

Los subsidios para riesgos del mercado forman parte del Programa de Prevención y Manejo de Riesgos, el cual contiene además los apoyos para desastres naturales y sanidades. Para los primeros se asignó el 48\% del presupuesto de dicho Programa en 2011, siendo sus principales componentes los programas de coberturas de precios y agricultura por contrato (SEGOB, 2010). El programa gubernamental de coberturas de precios inició en 1994, para subsidiar a los compradores de algodón y, dos años después, también a los de granos. A partir de 1997 se decidió apoyar igualmente a los productores. Por su parte, el programa de agricultura por contrato empezó a funcionar en 2003 y, desde entonces, la mayoría de las coberturas de precios solo se otorgan a los que estén inscritos en aquel programa, por lo que ambos están estrechamente vinculados. Sin embargo, la agricultura por contrato implica, aparte de los gastos por coberturas de precios, otros subsidios llamados "compensaciones de bases", que explicaremos más adelante.

Los apoyos para enfrentar las fluctuaciones de precios internacionales han sido los que han presentado el mayor dinamismo en los últimos años, en comparación con los otros dos pilares de la política agrícola ya mencionados. El programa de coberturas de precios apoyó a un volumen de productos que creció de 6.3 a 13,5 millones de toneladas entre 2005 y 2011, mientras que su presupuesto se incrementó de 497 a 11. 281 millones de pesos mexicanos (ASERCA, 2011b). Esta última suma representó el 15\% del presupuesto total asignado a SAGARPA (Secretaría de Agricultura, Ganadería, Desarrollo Rural, Pesca y Alimentación).

De acuerdo a cifras oficiales, en 2011 el gobierno mexicano apoyó con coberturas de precios, principal componente de la agricultura por contrato, un total de 13.7 
Tabla 1. México: principales granos producidos y apoyos del programa de coberturas de precios*

\begin{tabular}{l|c|c|c}
\hline Cultivo & $\begin{array}{c}\text { Superficie cosechada } \\
(\mathrm{Ha})\end{array}$ & $\begin{array}{c}\text { Volumen producción } \\
(\text { Ton) }\end{array}$ & $\begin{array}{c}\text { Volumen apoyado por } \\
\text { coberturas de precios (Ton) }\end{array}$ \\
\hline Maíz & $7.148,046$ & $23.301,878$ & $6.959,981$ \\
Sorgo & $1.768,382$ & $6.940,225$ & $2.812,081$ \\
Trigo & 678,553 & $3.676,707$ & $3.612,024$ \\
Cebada & 267,668 & 672,366 & - \\
Arroz & 41,748 & 216,676 & - \\
Total & $\mathbf{9 . 9 0 4 , 3 9 7}$ & $\mathbf{3 4 . 8 0 7 , 8 5 2}$ & $\mathbf{1 3 . 3 8 4 , 0 8 6}$ \\
Otros** & & & 345,914 \\
\hline Total nacional & $20.167,772$ & $331.786,019$ & $13.730,000$ \\
\hline
\end{tabular}

* Las cifras de superficie y producción son de 2.010 y las de apoyos por coberturas, de 2011

** Café, algodón, ganado (porcino y bovino), soja, cártamo y jugo de naranja.

Fuente: SAGARPA, 2012

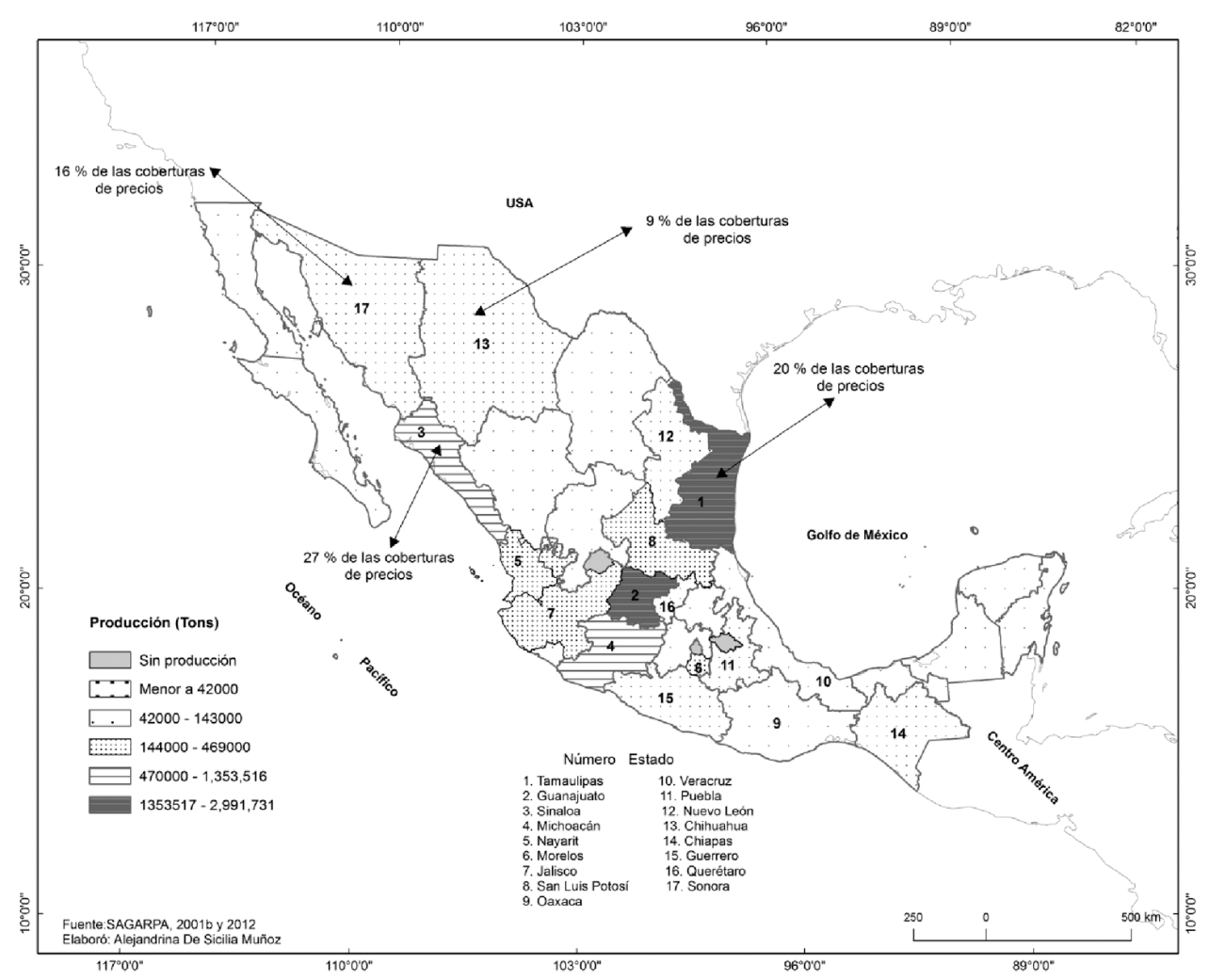

Figura 1. México: estados productores de sorgo y principales beneficiarios de las coberturas de precios (2010). 
millones de toneladas de bienes agropecuarios, la mayoría de los cuales (98\%) fueron granos: maíz (50\% del volumen apoyado), trigo (26\%) y sorgo (20\%) (Tabla 1). Ello significó que en ese año se subsidió al 38\% de la producción doméstica de granos, habiendo sido el trigo el más apoyado en relación a su producción, la cual se subsidió casi en su totalidad. Sin embargo, y al igual que en el resto de los programas de apoyos del gobierno (véase Fox y Haight, 2010b; FUNDAR, 2011), existe un elevado grado de concentración de los subsidios, tanto a nivel de los beneficiarios, como de las entidades o regiones del país apoyadas. Ello queda claro al conocer que en 2010 se apoyaron con coberturas de precios a solo 448,000 productores (ASERCA, 2011b), de un universo de alrededor de 3 millones que cultivan granos en México. La concentración geográfica de los apoyos existentes en otros programas relacionados con la agricultura, está presente también en el caso de las coberturas de precios, que han beneficiado mayoritariamente al norte del país: en 2011 el 70\% de los recursos asignados a ellas se dirigieron a los estados de Sinaloa (27\%), Tamaulipas (20\%), Sonora (16\%) y Chihuahua (9\%) (Figura 1). Similar porcentaje de concentración en las mismas entidades caracterizó al Ingreso Objetivo durante los años de su vigencia (FUNDAR, 2011), el cual, como ya señalamos, fue el principal programa de apoyo a la comercialización agrícola hasta 2006. Esta concentración de apoyos obedece a una histórica tendencia dentro de la política agrícola mexicana a beneficiar mayoritariamente a los productores "competitivos", es decir, a los grandes y medianos productores comerciales, los cuales se ubican fundamentalmente en el norte del país. Ellos fueron los beneficiarios de las inversiones públicas en infraestructua de riego que dieron lugar a los más prósperas áreas irrigadas del país, así como de los masivos subsidios para el uso del agua y la electricidad necesaria para bombear agua del subsuelo (Scott, 2010), lo cual ha sido una de las causas de la polarización de la agricultura mexicana (Fox y Haight, 2010a). En el caso concreto del programa de coberturas de precios, son ese tipo de productores los que pueden producir ciertos volúmenes mínimos y contar con organizaciones consolidadas (algunas con poder para cabildear los subsidios a nivel federal), así como con acceso a infraestructua de transporte y acopio.

\section{Características y funcionamiento de los programas de riesgos de precios}

Como ya mencionamos, las coberturas de precios se otorgan en el marco de la llamada agricultura por contrato. Esta constituye un mecanismo de abasto común para las agroempresas hortícolas de México (véase Echánove, 2005), así como para las que operan en la producción de otros bienes (tabaco, ganado porcino, cebada, etc.). Sin embargo, en todos estos casos los acuerdos se realizan sin intervención del gobierno, lo que distingue a dicho esquema contractual del aplicado a ciertos granos (maíz, trigo, sorgo y soya), en cuyo caso ha sido el gobierno el que ha diseñado y admi- 
nistrado el ya mencionado programa de agricultura por contrato. Esta ha sido definida por el gobierno como "la operación mediante la cual el productor vende al comprador antes de cosechar su producto, a través de la celebración de contratos de compra-venta, bajo condiciones específicas de volumen, calidad, tiempo, lugar de entrega, precio (o fórmula para la determinación de éste) y condiciones de pago" (SAGARPA, 2002). La mayoría de los contratos de compra-venta se firman entre organizaciones de productores y compradores, y son revisados y avalados por ASERCA (Apoyos y Servicios a la Comercialización Agropecuaria), institución perteneciente a la SAGARPA. En dichos acuerdos se establece el llamado "precio de contrato", que corresponde al precio internacional del grano en la Bolsa de Futuros de Chicago (CBOT) al momento de la firma del contrato. Para los productores, dicho precio constituye el mínimo a recibir (precio "piso"), pudiendo acceder a uno mayor si ocurren posteriores incrementos en las cotizaciones internacionales, mientras que para los compradores constituye el precio máximo a pagar (precio "techo"), siendo posible pagar posteriormente uno menor, en caso de que descienda el precio internacional del grano.

Sin embargo, para que ese esquema de riesgos funcione es necesario proteger los volúmenes de grano contratados mediante la compra de "coberturas de precios" en la Bolsa de Futuros de Chicago (CBOT), mercado donde se fijan la mayoría de los precios internacionales de esos bienes. Por supuesto, la compra de dichas coberturas conlleva un costo ("prima") que, hasta 2010, ASERCA ponía inicialmente en su totalidad; sin embargo, para 2011 se requirió que los productores pusiesen el 5\% de dichas primas, mientras que las empresas consumidoras de granos y las comercializadoras, un 50\%. Ahora bien, dichas coberturas generan siempre una ganancia en la Bolsa, dependiendo de si los precios subieron o bajaron. De esas ganancias, ASERCA recupera el $40 \%$ en el caso de productores o consumidores y el 60\% en el caso de las comercializadoras (ASERCA, 2011c). Otra regla de la agricultura por contrato es que el grano de los productores debe ser pagado al tipo de cambio establecido por el Banco de México ("Fix"), vigente al momento de entrega del producto en las bodegas.

Aparte del precio de contrato, los compradores quedan obligados a pagar a los productores una cantidad de dinero por tonelada de grano por concepto de "bases". El monto de éstas lo fija y publica ASERCA, pero generalmente no lo hace antes de las siembras, como debería ser para que los productores pudiesen tomar decisiones, sino con posterioridad a ellas. El monto de las bases es supuestamente fijado en función de diversos factores (costo de traer el grano a México desde ciertos puntos de $\mathrm{EU}$; costos de almacenamiento, fletes y financieros entre zonas productoras nacionales y zonas de consumo, y disponibilidad del producto). Si las bases son altas benefician a los productores y, si son bajas, a las empresas. Algunas firmas entrevistadas señalaron que las bases las pueden negociar con ASERCA a nivel federal, hecho sabido también por muchos productores, por lo que realmente son un instrumento 
del gobierno para favorecer a alguno de esos agentes en función de factores políticos. Aparte del tema de las primas, el gobierno otorga otro subsidio llamado "compensaciones de bases", calculadas de acuerdo a las fluctuaciones que las bases hayan tenido entre el momento de su fijación y el de la entrega del grano. Si la diferencia es positiva, el gobierno entrega este apoyo directamente a los productores y, si es negativa, a los compradores.

\section{La agricultura por contrato en el sorgo de Tamaulipas}

Los productos agrícolas mas relevantes en México por el área que ocupan son los granos, que en 2010 contribuyeron con casi la mitad de la superficie total cosechada (Tabla 1). El segundo grano en importancia, después del maíz, es el sorgo, cuya producción en ese año fue de 6.9 millones de toneladas, la cual se concentra mayoritariamente en la parte centro y norte del país (Figura 1). El principal estado productor es Tamaulipas, que en ese año contribuyó con el 43.1\% del volumen cosechado (2.9 millones de toneladas), seguido por Guanajuato, que aportó el 19.5\% (1.3 millones de toneladas) y Sinaloa (767 mil toneladas) (11\%) (Tabla 2). La mayoría de la cosecha de Tamaulipas procede de la zona norte, donde se ubican los principales distritos de riego y las áreas de secano del municipio de San Fernando. Para apoyar la comercialización del grano, el gobierno implementó a fines de 2005 el programa de agricultura por contrato, en el cual participan casi 12.000 productores, la mayoría de los cuales son medianos y grandes, es decir, los que cultivan al menos 50 hectáreas de sorgo.

Tabla 2. México: principales estados productores de sorgo grano (2010).

\begin{tabular}{l|c|c|c}
\hline Estado & $\begin{array}{c}\text { Superficie cosechada } \\
\text { (Has) }\end{array}$ & $\begin{array}{c}\text { Volumen de producción } \\
\text { (Ton) }\end{array}$ & $\begin{array}{c}\text { \% de la producción } \\
\text { Tamaulipas }\end{array}$ \\
Guanajuato & 857,047 & $2.991,731$ & 43,1 \\
Sinaloa & 220,745 & $1.353,518$ & 19,5 \\
Michoacán & 217,354 & 767,887 & 11,1 \\
Nayarit & 114,173 & 469,391 & 6,7 \\
Morelos & 51,832 & 249,684 & 3,6 \\
Jalisco & 41,567 & 206,882 & 3,0 \\
San Luis Potosí & 33,334 & 188,255 & 2,7 \\
Otros & 55,717 & 144,081 & 2,1 \\
Total & 176,613 & 568,796 & 8,2 \\
\hline
\end{tabular}

Fuente: SAGARPA, 2012 
La mayoría del sorgo es del ciclo otoño-invierno, sembrándose el grano entre octubre y diciembre y cosechándose en mayo-junio. En la cadena de comercialización del sorgo existe un agente entre las organizaciones de los productores y las empresas compradoras, que son las firmas comercializadoras. Estas reciben el grano de los productores y se vinculan con los compradores, dado que los agricultores no cuentan con la infraestructura y logística necesaria para hacerlo directamente. Existen alrededor de 60 empresas comercializadoras, pero las cinco mayores concentran poco más de la mitad del sorgo bajo contrato. Estas acopian el grano, lo seleccionan, secan, almacenan y, si así lo acuerdan con el comprador, lo envían, para lo cual algunas cuentan con flotillas de transporte propias y acceso al ferrocarril. Todas estas labores son pagadas por los compradores del grano, o sea, los fabricantes de alimentos animales y/o productores avícolas, porcícolas y cebaderos de bovinos, mientras que el secado del grano lo pagan los productores. Las comercializadoras también otorgan financiación, tanto a los productores (previo aseguramiento de sus cosechas), como a los compradores. Sin embargo, no todo el grano que acopian dichos intermediarios lo hacen bajo el programa oficial de contratos, ya que también se dedican a comprar y vender grano en el mercado libre, participando en ambos escenarios en función de las expectativas de precios, subsidios y ganancias.

Las principales comercializadoras son empresas exitosas y capitalizadas. Algunas cuentan con modernas bodegas para almacenar y secar el grano en diversos estados del norte del país, mientras que una de ellas también produce carne de pollo, huevo y alimentos animales. La gran mayoría del sorgo de Tamaulipas (el 85\%) sale de este estado, dirigiéndose a diversos estados y regiones del país (Jalisco, Puebla, Veracruz, La Laguna, etc.). Entre éstos destaca Jalisco, a donde se envía alrededor del 60\% del sorgo contratado, ya que constituye el principal productor pecuario de México (el primero en huevo, leche de bovino, carne de cerdo y de ave). El comprador más relevante del sorgo tamaulipeco es la firma avícola Bachoco, cuyas adquisiciones representan casi la tercera parte de lo vendido bajo contrato en el estado. Esta empresa consume en promedio 2 millones de toneladas de granos al año, la mitad de las cuales proviene de compras en el mercado doméstico y, la otra, de importaciones de Estados Unidos (entrevista directa, Bachoco, 2009).

Para poder abastecer el mercado mexicano de huevo y carne de pollo, así como de los alimentos animales requeridos para su producción, Bachoco se ha diversificado geográficamente, contando con 720 granjas y 14 plantas de alimentos animales y procesadoras de aves ubicadas en 16 estados del país (Bachoco, 2010). Los otros compradores del sorgo tamaulipeco son en su mayoría fabricantes de alimentos animales, entre los que figuran firmas transnacionales como Malta Cleyton, adquirida en 2008 por la compañía francesa Evialis, y Agribrands Purina, subsidiaria de la estadounidense Cargill. También compran grano porcicultores y engordadores (cebaderos) de bovinos. 
En 2009 en Tamaulipas se comercializaron bajo agricultura por contrato 1.3 millones de toneladas de sorgo, casi la mitad de lo apoyado a nivel nacional. En años anteriores dicho programa protegió mayores volúmenes de sorgo, pero presentó problemas que revelaron sus puntos vulnerables y que, dada su importancia, los exponemos en el siguiente apartado.

\subsection{La problemática del $2008-2009$}

Para ese año, ASERCA validó en Tamaulipas contratos entre productores y compradores por un total de 2.3 millones de toneladas de sorgo, para las cuales esa institución adquirió coberturas de precios en el mercado de futuros. Sin embargo, meses después, al término de la cosecha, solo se comercializaron 1.5 millones de toneladas, debido a siniestros climáticos (sequía en zonas de secano) pero, sobre todo, a la falta de veracidad en los contratos presentados ante ASERCA, con el fin de obtener los mayores subsidios posibles (volúmenes de grano registrados mayores a los que realmente se cosecharían, auto-ventas de las firmas comercializadoras, etc.). A pesar de que supuestamente dicha institución es la encargada de analizar y avalar los contratos, realizó las compras de coberturas por el total solicitado, desperdiciando así enormes recursos para proteger granos que nunca se vendieron dentro del programa.

Ante ello, ASERCA decidió apoyar para el siguiente año (2009) solamente 1.6 millones de toneladas de sorgo, que representaban el $70 \%$ de la cosecha esperada. Pero entonces se presentaron nuevos problemas, primeramente porque ASERCA inició el período de registro de contratos muy tardíamente (28 de enero), cuando los productores ya habían sembrado su sorgo 2-3 meses antes. Pero solo hasta un mes después de dicho inicio empezaron a ingresar los primeros contratos (fines de febrero) debido a que las empresas compradoras no querían participar en el programa oficial, ya que estaban esperando ver qué pasaba con el tipo de cambio que iba al alza, en el contexto del proceso devaluatorio anteriormente descrito. Para febrero de 2009, el tipo de cambio había llegado a \$15 pesos mexicanos por USD, en comparación con los \$10.9 de cinco meses antes.

En ese contexto, Bachoco ofreció firmar contratos a un tipo de cambio de 13.5 pesos por USD (en vez de \$15), propuesta que fue rechazada por los productores. Ante esto, la empresa restringió sus compras bajo el programa oficial, adquiriendo solo la mitad del volumen de sorgo que usualmente compraba en Tamaulipas. Otros compradores importantes, como LALA y Agribrands Purina, optaron por no participar en el programa y adquirir a menores precios el grano que necesitaran en el mercado libre. Como resultado, en 2009 solo se firmaron contratos por 1.3 millones de toneladas de sorgo, por lo que el gobierno estatal y los productores demandaron al gobierno federal apoyos para la comercialización del grano que quedó fuera del pro- 
grama. Sin embargo, el gobierno solo amplió el esquema de contratos para otras 200.000 toneladas a ser adquiridas por porcicultores, a quienes el gobierno les otorgaría el 100\% del costo de las primas para la adquisición de coberturas de precios, sin recuperación alguna por parte del gobierno. A cambio de ello, a los porcicultores se les exigía pagar al productor un determinado precio por el grano. Para 2010 y 2011 el volumen de sorgo bajo agricultura por contrato aumentó, habiendo sido de 2.1 y 1.9 millones de toneladas, respectivamente (ASERCA, 2012a).

\section{El sorgo bajo contrato en Guanajuato}

Guanajuato es la segunda entidad productora de sorgo del país. Entre 2008 y 2009 se incrementó el volumen contratado bajo agricultura por contrato, de 447 a 607 mil toneladas, cifra esta última que representó la mitad de la producción del estado. Para 2010 se contrataron 563 mil toneladas, pero en 2011 este rubro se desplomó a 256 mil toneladas, por las razones que daremos posteriormente.

Algunas de las principales empresas compradoras de sorgo son las mismas que lo adquieren en Tamaulipas, como es el caso de Bachoco, Malta Cleyton y Agribrands Purina. A estos compradores habituales se suma una larga lista de firmas elaboradoras de alimentos animales y engordadores de ganado. Solo un $40 \%$ del grano queda en Guanajuato, mientras que el restante porcentaje se dirige a otros estados del país, entre los que destaca Jalisco. Bachoco ha sido el comprador más relevante (en 2008 adquirió casi la cuarta parte del sorgo contratado), con un promedio de 100.000 toneladas anuales del grano, que destina a su planta de alimentos balanceados ubicada en Guanajuato, sede también de sus oficinas corporativas y de una planta procesadora de aves. Los productos finales (carne de pollo y huevo) se destinan al abasto de la capital del país. Agribrands Purina (Cargill) también tiene en esa entidad sus oficinas corporativas, así como dos plantas de alimentos balanceados, aunque cuenta con otras ocho ubicadas en diversas zonas del país (Baja California, Sonora (2), Nuevo León, Jalisco, Estado de México, Puebla y Yucatán). Malta Cleyton, otro de los principales compradores, posee una fábrica de alimentos balanceados en Guanajuato y otras siete distribuidas en otras entidades (Tlaxcala, Sinaloa, Nuevo León, Yucatán, Distrito Federal, Jalisco y Tabasco). Por su parte, Incubadora Hidalgo (Pilgrim's Pride) cuenta con una planta en el vecino estado de Querétaro y dos en San Luis Potosí e Hidalgo.

Por las mismas razones que en Tamaulipas, en Guanajuato las comercializadoras han jugado el papel de intermediarios entre productores y compradores, acopiando la mayoría del sorgo que se vende bajo contrato. El resto del grano es vendido por productores (medianos y grandes) que, de manera individual o a través de organizaciones, contratan directamente con las empresas compradoras. Es interesante señalar 
que la mayor parte de las comercializadoras se presentan como "organizaciones de productores", adoptando el título de Sociedades de Producción Rural (SPR), siendo en realidad acopiadores estatales o regionales de granos. El resto de las comercializadoras adoptan la figura jurídica de sociedades anónimas, como es el caso de IAGROCEN (Integradora Agropecuaria del Centro SA de CV), que en 2008 llegó a acopiar el 60\% del sorgo contratado en Guanajuato (276,000 toneladas). Esta empresa, fundada a fines de 2005 por un relevante comerciante de granos de la entidad, llegó a contar con 9.500 socios pertenecientes a 39 organizaciones de productores, en su mayoría de Guanajuato, aunque también de los estados de Jalisco y Michoacán. Se dedicaba a la comercialización de sorgo, maíz y trigo, tanto del comprometido bajo agricultura por contrato como del que vendía en el mercado libre. Las funciones de IAGROCEN incluían realizar los trámites de los contratos ante ASERCA, contactar a los compradores para que adquiriesen el grano almacenado por los productores, y otorgarles a éstos financiamiento (Valdés, 2009, entrevista directa). Las empresas compradoras pagaban el grano de los productores a través de IAGROCEN, a la cual también entregaba el gobierno ciertos subsidios para que los transfiriese a los productores. En 2009, IAGROCEN continuó siendo la comercializadora de sorgo más relevante de la entidad, aunque el volumen colocado bajo contrato se redujo a 150.000 toneladas (25\% del sorgo contratado en el estado) (ASERCA, 2012b). Al año siguiente, tanto productores como entidades gubernamentales demandaron a IAGROCEN por fraude, dado que hasta entonces no había entregado a los agricultores el total de los pagos por sus cosechas de 2008 y 2009. Tampoco había liquidado los créditos que le otorgó la Financiera Rural y SEDAGRO, instituciones del gobierno federal y estatal (FOROLACFG, 2010; Albañil, 2010; Domínguez, 2011).

El esquema oficial de agricultura por contrato también confrontó otros problemas. A fines de 2008, los contratos entre productores y firmas compradoras habían sido firmados y validados por ASERCA con anterioridad a la cosecha del sorgo, pero al acercarse la fecha de ésta (noviembre-diciembre) inició el proceso de devaluación del peso mexicano reseñado anteriormente. Las grandes firmas compradoras manifestaron que no cumplirían con dichos contratos, ya que el tipo de cambio vigente implicaba para ellas mayores erogaciones por el grano. Ello, enmarcado además en el contexto de alza de los precios internacionales de esos bienes iniciada en 2007 , que para mediados de 2008 había llevado el precio del sorgo hasta 300 USD por tonelada. Después de un proceso conflictivo entre productores, compradores y gobierno, los segundos ofrecieron pagar el sorgo a un tipo de cambio de $\$ 12.50$ (y no a $\$ 15$ que era el vigente), lo cual se formalizó mediante la modificación de los contratos ya firmados.

A lo anterior, durante 2009 y 2010 se sumaron otros motivos para incumplir los contratos. En el primer año, los productores solo entregaron a los compradores 298 mil toneladas de sorgo, lo que significó la mitad del grano comprometido en los con- 
tratos, debido tanto a la disminución de cosechas por la sequía que afectó a Guanajuato, como al desvío de grano hacia el mercado libre, donde los precios fueron superiores a los recibidos bajo agricultura por contrato. Ello significó un enorme desperdicio de recursos federales, ya que el gobierno erogó sumas millonarias por el pago de primas para proteger en la Bolsa de Chicago la totalidad del volumen contratado. El gobierno también tuvo que pagar a las empresas compradoras las ganancias que los volúmenes de granos no entregados habían generado como efecto del movimiento de precios en dicha Bolsa, tal y como lo establece la normativa del programa.

Para 2011, y como ya señalamos, los volúmenes contratados de sorgo en Guanajuato se desplomaron (256 mil toneladas), habiendo sido de menos de la mitad que el año anterior. Ello, debido fundamentalmente a que el precio del grano en el mercado libre $(\$ 3,980$ por tonelada) fue mayor al precio de contrato $(\$ 3,490$ por tonelada), por lo que a los productores no les resultó atractivo participar en el programa. A la fecha (mayo 2012), ya han empezado a sembrar el sorgo los que cuentan con riego, pero ASERCA señala que los trámites para participar en agricultura por contrato no se iniciarán hasta agosto-septiembre, debido al proceso de elecciones presidenciales que se llevará a cabo en julio de ese año. Esto, hace evidente no solo la acostumbrada falta de información para el productor en el momento de siembra, sino la politización de los instrumentos de apoyo gubernamentales.

\section{Reflexiones finales}

Los productores agrícolas afrontan riesgos provenientes de distintas fuentes: riesgos de la producción (clima, plagas, enfermedades y cambios tecnológicos); riesgos ecológicos (producción, cambio climático (inundaciones, sequías), manejo de los recursos naturales); riesgos de mercado (variabilidad de precios de insumos y productos, volúmenes posibles de comercializar, requerimientos de calidad, seguridad, nuevos productos, etc.); riesgos regulatorios o institucionales (políticas agrícolas, seguridad alimentaria y regulaciones medio ambientales); riesgos financieros (acceso al crédito, variación de tasas de interés, capacidad de pago de adeudos) y riesgos de recursos humanos (acceso a mano de obra) (Harwood et al., 1999 y Hardaker et al., 2004 (citados en OECD, 2009); OECD, 2000, 2009, 2011b; Banco Mundial, 2005; Garrido y Badají, 2009). En el caso de países en desarrollo, la falta de infraestructura y los mercados poco desarrollados constituyen también importantes fuentes de riesgo (Banco Mundial, 2005), así como la frecuente probabilidad de robo de equipo, maquinaria y cosechas.

En este artículo analizamos los riesgos de mercado, específicamente los relacionados con la variación de precios internacionales de los granos. Existe una vasta lite- 
ratura y amplio debate sobre lo oportuno o no de la ingerencia de los gobiernos para establilizar los precios internacionales, sin haber llegado, hasta hoy, a algún consenso a nivel mundial. No obstante ello, la mayoría de los países de la OECD continúan aminorando los efectos de la variación de dichos precios en sus productores, como lo demostró el hecho de que los incrementos habidos en 2007 no fueron completamente transmitidos a sus mercados domésticos (OECD, 2009).

Los riesgos del mercado para la mayoría de los productores de granos en México son un factor de preocupación tan importante como los de índole climática, al igual que sucede en diversos países (véase para España, Garrido y Bardají, 2009). En particular la falta de agua o sequía es preocupante, dado que dos terceras partes de la superficie agrícola cosechada en México es de secano (13 millones de hectáras). Pero para la mayoría de los productores que cuentan con riego, las fluctuaciones desfavorables de precios han constituido su problema recurrente. Durante décadas, los productores mexicanos recibieron bajos precios por sus granos, como efecto de su masiva importación a precios subsidiados ("dumping") procedentes de Estados Unidos (Wise y Rakocy, 2010). Esta situación cambió para los productores adscritos al programa de agricultura por contrato, sobre todo a partir de 2007 en que inició el alza de los precios internacionales de los granos, los cuales, después de descender entre mediados de 2008 y fines de 2009, han vuelto a incrementarse a partir de 2010 (CEPAL-FAO-IICA, 2011).

Es indudable que para los productores los contratos les dan mayor certidumbre sobre la venta de sus granos a precios mínimos conocidos de antemano, lo cual es mejor que vender a intermediarios locales que frecuentemente no les liquidan o les ofrecen menores precios. También haber hecho contratos les permite la obtención de créditos y, por supuesto, el acceso a los subsidios del gobierno (primas y compensaciones de bases). Por su parte, las empresas aseguran su abasto de granos de cierta calidad y a menores precios que los importados, además de protegerse ante futuras alzas en los precios internacionales de los granos. Los subsidios obtenidos del gobierno, en especial por concepto de primas, les evitan realizar desembolsos millonarios.

Sin embargo, el programa estudiado es vulnerable y tiene importantes fallas o limitantes que resumimos a continuación:

\section{a) Incumplimiento de contratos: clima, precios relativos y tipo de cambio}

Dichos incumplimientos ocurren tanto por parte de productores como de empresas consumidoras de granos, y se refieren a los volúmenes de estos bienes que fueron contratados pero no entregados por los productores a sus organizaciones o a las empresas consumidoras, tanto por motivos de desastres climáticos (sequías, heladas, etc.), como por desvíos intencionales de granos hacia el mercado libre, cuando los 
precios en éste son mayores a los precios de contrato. Dado que el gobierno subsidió la compra de coberturas por el total del grano contratado, dichos incumplimientos representan un despilfarro de recursos federales. Como ya hemos reseñado, las empresas incumplen los contratos cuando las modificaciones en el tipo de cambio peso mexicano-dólar estadounidense al que tienen que pagar los granos no les favorecen.

En un contexto de creciente cambio climático, que ocasiona el descenso de los volúmenes cosechados de granos, la probabilidad de incumplimientos en el esquema de contratos es altísima. Dichos descensos, aunados a otros factores, entre los que figura la retención de oferta con fines especulativos por parte de las grandes firmas alimentarias, presionan hacia el alza a los precios en el mercado libre, los cuales frecuentemente alcanzan niveles superiores a los precios de contrato (precio internacional más bases). En estos casos, los productores no encuentran incentivos para participar en el esquema gubernamental de agricultura por contrato. Por otra parte, la volatilidad de los precios internacionales de los bienes agrícolas durante los últimos años, en la que ha influido la especulación y la mayor asociación de los mercados de bienes primarios con los mercados financieros (De Schutter, 2010; CEPAL-FAO-IICA, 2011; UNCTAD, 2009, 2011; Torero, 2011; INTAL, 2010), es también un factor de vulnerabilidad para el esquema contractual. Otro es el tipo de cambio, cuyas variaciones están igualmente influidas por movimientos especulativos, y que confronta los intereses de productores y empresas, siendo el mayor poder de éstas el factor que ha decidido a su favor, como vimos en los casos expuestos.

\section{b) Baja cobertura nacional y concentración de beneficiarios}

Hemos visto que solo son apoyados con agricultura por contrato y, por ende, con coberturas de precios, el 15\% de los productores de granos y casi el $40 \%$ de su producción. Esos productores son mayoritariamente medianos y grandes, y constituyen, junto con las comercializadoras y las grandes empresas productoras de alimentos animales, los principales beneficiarios de los subsidios del gobierno. Además, y como ya vimos, algunas de las supuestas organizaciones de productores apoyadas son, en realidad, acaparadores de granos que frecuentemente se quedan con parte o todos los apoyos dirigidos a los productores directos. En resumen, se apoya fundamentalmente a quien menos lo necesita. Como ya mencionamos, esta concentración de los apoyos no es una característica solo del programa analizado, sino de la mayoría de los subsidios dirigidos al sector agropecuario mexicano y cuyo efecto ha sido la agudización de la desigualdad (véase FUNDAR, 2011; Fox y Haight, 2010b; Scott, 2010; Maldonado, 2010; Merino, 2010; Berlanga, 2010; Rello, 2008 y Steffen, 2007). En 2009, por ejemplo, la mitad del gasto público agrícola en México se dirigió al 10\% de los productores más ricos (Banco Mundial, 2009, citado en Fox y Haight, 2010a). 


\section{c) Burocracia, ineficiencia y especulación}

Existe una excesiva burocratización e ineficiencia en ASERCA, lo que se manifiesta, entre otras cosas, en la falta de oportunidad en la publicación de los lineamientos del programa de agricultura por contrato, en el desfase de la apertura de trámites (mucho después de las siembras), y en los excesivos retrasos en los pagos de los apoyos a los productores (usualmente mas de un año). Por otra parte, el esquema contractual da lugar a la especulación por parte de los agentes participantes, así como de despachos de asesores. La presencia de corrupción en el manejo de los recursos por parte de las comercializadoras es frecuente, como lo demuestra el caso reseñado de Guanajuato.

Los subsidios a la comercialización en México constituyen un intento por paliar los efectos que en el sector agropecuario ha tenido la retirada del Estado (asesoría, crédito, investigación) y la radical apertura comercial producto de la adhesión al TLCAN. Para ello, por un lado otorga millonarios subsidios a las firmas compradoras para que adquieran los granos domésticos en vez de importarlos y, por otro, apoya a productores importantes para tratar de evitar que enfrenten problemas de comercialización de sus cosechas y realicen movilizaciones sociales.

No planteamos aquí el que no deba existir una política gubernamental de apoyo a los productores respecto a los riesgos de mercado, sino que el esquema contractual tal y como funciona hasta hoy ha demostrado no ser un medio adecuado. Tendrán que implementarse o reforzarse un conjunto de instrumentos de política agrícola que lleguen a mayor número de auténticos productores, cuya definición rebasa el objetivo de este artículo. En este sentido, compartimos el enfoque holístico de la OECD que señala que el manejo de riesgos constituye un sistema en el que ninguna estrategia o política puede ser implementada aisladamente, sino que tienen que considerarse las interacciones entre las intervenciones gubernamentales, la naturaleza de los riesgos y las estrategias de los productores (OECD, 2009). Antón y Giner (2005), al estudiar los impactos que los distintos apoyos gubernamentales tienen en los riesgos del productor, su ingreso y producción, señalan que los más eficientes en cuanto a reducción de riesgos son los pagos por área o superficie debido a su eficiencia como trasmisores de ingresos, opinión esta última compartida por la OECD (2011a). Desgraciadamente, en México este tipo de apoyos (PROCAMPO) ha decrecido en un 40\% en términos reales durante 1994-2010 (ASERCA, 2011a), habiendo sido su presupuesto en 2011 inferior al otorgado a otros programas dirigidos a productores "comerciales" (SEGOB, 2010). Y, en conjunto, los apoyos a los productores mexicanos han decrecido en las últimas dos décadas, habiendo pasado del $28 \%$ de su ingreso bruto en 1991-93 al 12\% en 2008-2010, porcentaje éste menor al promedio de los países de la OECD (20\%) (OECD, 2010 y 2011b). 


\section{Agradecimientos}

Agradezco el financiamiento para la realización de esta investigación por parte de CONACYT (Consejo Nacional de Ciencia y Tecnología), proyecto no. 155376, así como las valiosas observaciones de los evaluadores anónimos.

\section{Referencias}

Albañil, S. (2010) Estafan a campesinos. Periódico AM, 14 de junio.

ALLTECH (2012) Global Feed Summary. $<$ http://www.ifif.org $>$

Anton, J. y Giner, C. (2005) Can risk reducing policies reduce farmer's risk and improve their welfare? Organisation for Economic Co-operation and Development (OECD). $<$ http://ageconsearch.umn.edu/bitstream/24578/1/cp05an01.pdf>

Appendini, K. (2008) Tracing the maize-tortilla chain. UN Chronicle United Nation, 2-3, 66-72.

ASERCA (Apoyos y Servicios a la Comercialización Agropecuaria) (2011a) Informe de resultados y de impacto económico y social del componente PROCAMPO para Vivir Mejor. Claridades Agropecuarias, 213, 13-29.

ASERCA (Apoyos y Servicios a la Comercialización Agropecuaria) (2011b) Cobertura de precios de productos agropecuarios. Claridades Agropecuarias 220, 3-15.

ASERCA (Apoyos y Servicios a la Comercialización Agropecuaria) (2011c) Apertura de Ventanillas Agricultura por Contrato Ciclo Agrícola PV 2011. $<$ http://www.infoaserca.gob.mx/>

ASERCA (Apoyos y Servicios a la Comercialización Agropecuaria) (2012a) $<$ http://www.infoaserca.gob.mx/cobertu$\mathrm{ras} /$ ConsultaEstado.asp?edo $=10>$
ASERCA (Apoyos y Servicios a la Comercialización Agropecuaria) (2012b) Informe del Programa de Prevención y Manejo de Riesgos. <http://www.infoaserca.gob.mx/coberturas/ConsultaMexico. asp>

Bachoco (2009) Entrevista directa con el Gerente de Compras Nacionales, Celaya, Guanajuato.

Bachoco (2010).

$<$ http://www.bachoco.com.mx>

Banco Mundial (2005) Managing agricultural production risk. Innovations in developing countries.

$<$ http://www-wds.worldbank.org $>$

Banco Mundial (2009) México: análisis del gasto público en el desarrollo agrícola y rural. Informe \#51902-MX. <http://wwwwds.worldbank.org>

Berlanga, H. (2010) ¿Qué programas llegan a las comunidades de bajos ingresos?, en Fox, J. y Haight, L. (coords.) Subsidios para la desigualdad. Las políticas públicas del maíz en México a partir del libre comercio. Dissa Impresores.

CEDRSSA (Centro de Estudios para el Desarrollo Rural Sustentable y la Soberanía Alimentaria) (2007) Metaevaluación de programas de la SAGARPA dirigidos a productos agrícolas básicos. Resultados generales.

$<$ http://www.cedrssa.gob.mx>

CEPAL-FAO-IICA (2011) Volatilidad de precios 
en los mercados agrícolas (2000-2010): implicaciones para América Latina y opciones de políticas, Boletín 1.

De Schutter, O. (2010) Food commodities speculation and food price crisis, United Nations special rapporteur on the right to food, Briefing Note 02.

Domínguez, C. (2011) Exigen productores a IAGROCEN les pague el adeudo de 2008. Periódico El Correo, 16 de junio.

Echánove, F. (2009) Políticas Públicas y Maíz en México: el Esquema de Agricultura por Contrato, Anales de Geografía, 29 (2), 824.

Echánove, F. y Steffen, C. (2005) Agribusiness and farmers in México: the importance of contractual relations. The Geographical Journal, 171 (2), 166-176.

FOROLACFR (Foro Latinoamericano y del Caribe de Finanzas Rurales) (2010) Fraude millonario a productores agrícolas. $<$ http://ci.forolacfr.org >

Fox, J. y Haight, L. (2010a) La política agrícola mexicana: metas múltiples e intereses en conflicto, en Fox, J. y Haight, L. (coords.) Subsidios para la desigualdad. Las políticas públicas del maíz en México a partir del libre comercio. Dissa Impresores.

Fox, J. y Haight, L. (2010b) Síntesis de los hallazgos: tendencias en la política de subsidios agrícolas, en Fox, J. y Haight, L. (coords.) Subsidios para la desigualdad. Las políticas públicas del maíz en México a partir del libre comercio. Dissa Impresores.

FUNDAR, Centro de Análisis e Investigación (2011).

<http://www.subsidiosalcampo.org.mx>

Garrido, A. y Bardaji, I. (2009) Estrategias para la gestión de riesgos y crisis en la agricultura española. Revista Española de
Estudios Agrosociales y Pesqueros, 221, 175-205.

Hardaker, J., Hurine, R, Anderson J, y Lien, G. (2004) Coping with risk in agriculture, CABI Publishing.

Harwood, J., Heifner, R., Coble, K., Perry, J. y Somwaru, A. (1999) Managing risk in farming: concepts, research and analysis, USDA Agricultural Economic Report No. 774, Economic Research Service.

IFIF (International Feed Industry Federation) (2011) Annual Report.

$<$ http://www.ifif.org/>

INTAL (Instituto para la Integración de América Latina y el Caribe) (2010) América Latina y los precios de las materias primas. Situación y perspectivas. Carta Mensual INTAL, 162. <http://www.iadb.org/>

Maldonado, M. (2010) ¿A quién le dan pan que llore? Percepciones de beneficiarios del programa Procampo, en Fox, J. y Haight, L. (coords.) Subsidios para la desigualdad. Las políticas públicas del maíz en México a partir del libre comercio. Dissa Impresores.

Merino, M. (2010) Los programas de subsidios al campo: las razones y las sinrazones de una política mal diseñada, en Fox, J. y Haight, L. (coords.) Subsidios para la desigualdad. Las políticas públicas del maíz en México a partir del libre comercio. Dissa Impresores.

OECD (Organización para la Cooperación y el Desarrollo Económicos) (2000) Income Risk Management in Agriculture, OECD Paris.

OECD (Organización para la Cooperación y el Desarrollo Económicos) (2009) Managing risk in agriculture: a bolistic approach. $<$ http://www.oecd.org/agriculture/policies/risk>

OECD (Organización para la Cooperación Económica y el Desarrollo) (2010) 
Agricultural policies in OECD countries 2010 at a glance. <http://www.oecd-ilibrary.org >

OECD (Organización para la Cooperación Económica y el Desarrollo) (2011a) Agricultural policy monitoring and evaluation 2011. OECD Countries and Emerging Economies. <http://www.oecdilibrary.org>

OECD (Organización para la Cooperación Económica y el Desarrollo) (2011b) Risk management in agriculture: what role for governments? $<$ http://www.oecd-ilibrary.org>

Paz, M. y Palacio, V. (2009) Política agrícola en México: reformas y resultados: 19882006. Observatorio de la Economía Latinoamericana, 119.

$<$ http://www.eumed.net/cursecon/ecolat/mx/2009/htm>

Reinhardt, N. y Peres, W. (2000) "Latin America's new economic model: micro responses and economic restructuring World Development, 28 (9), 1543-1566.

Rello, F. (2008) Inercia estructural y globalización: la agricultura y los campesinos más allá del TLCAN, Trabajo de discusión \#20. Washington y Massachusetts: Washington Office on Latin America and Global Development and Environment Institute.

SAGARPA (Secretaría de Agricultura, Ganadería, Desarrollo Rural, Pesca y Alimentación) (2002) Reglas de operación del Programa de Apoyos Directos a la Comercialización y Desarrollo de Mercados, Diario Oficial de la Federación 13 de marzo, p. 41-50.

SAGARPA (Secretaría de Agricultura, Ganadería, Desarrollo Rural, Pesca y Alimentación) (2012).

<http://www.siap.sagarpa.gob.mx>
Scott, J. (2010) Subsidios agrícolas en México: ¿quién gana y cuánto?, en Fox, J. y Haight, L. (coords.) Subsidios para la desigualdad. Las políticas públicas del maíz en México a partir del libre comercio. Dissa Impresores.

SEGOB (Secretaría de Gobernación) (2010) Diario Oficial de la Federación, Presupuesto de Egresos de la Federación, 7 de diciembre. <http://dof.gob.mx>

Steffen, C. (2007) La focalización de los subsidios a los granos en México. Polis 3 (2), 69-103.

Torero, M. (2011) Understanding the causes of food price volatility and mitigating its consequences. Brussels Policy Briefing $\mathrm{n}^{\mathrm{o}} 25$. $<$ http://brusselsbriefings.net/past-briefings/no-25-food-price-volatility>

UNCTAD (2009) The global economic crisis: systemic failures and multilateral remedies.

$<$ http://www.unctad.org/en/docs/gds2009 1_en.pdf>

Valdés, J. (2009) Gerente de Comercialización de IAGROCEN, entrevista personal, 19 de septiembre.

Wise, T. (2010) Exportaciones de Estados Unidos anulan efectos de Procampo. Desarrollo Porcícola, 120, 14-16, octubrenoviembre.

Wise, T. y Rakocy, B. (2010) Hogging the gains from trade. The real winners from US trade and agricultural policies. GDAE Policy Brief 10-01, Global Development and Environment Institute, Tufts University, Medford, Mass.

Yúnez, A. y Barceinas, F. (2000) Efectos de la desaparición de la CONASUPO en el comercio y en los precios de los cultivos básicos. Estudios Económicos, 2, 189-227. 